\title{
Lateral femoral notch sign and posterolateral tibial plateau fractures and their associated injuries in the setting of an anterior cruciate ligament rupture
}

\author{
Alexander Korthaus ${ }^{1} \cdot$ Malte Warncke $^{2} \cdot$ Geert Pagenstert $^{3} \cdot$ Matthias Krause $^{1} \cdot$ Karl-Heinz Frosch $^{1,4} \cdot$ Jan \\ Philipp Kolb ${ }^{1}$
}

Received: 14 July 2021 / Accepted: 26 July 2021 / Published online: 2 August 2021

(c) The Author(s) 2021

\begin{abstract}
Introduction ACL injury is one of the most common injuries of the knee joint in sports. As accompanying osseous injuries of the ACL rupture a femoral impression the so-called lateral femoral notch sign and a posterolateral fracture of the tibial plateau are described. However, frequency, concomitant ligament injuries and when and how to treat these combined injuries are not clear. There is still a lack of understanding with which ligamentous concomitant injuries besides the anterior cruciate ligament injury these bony injuries are associated.

Materials and methods One hundred fifteen MRI scans with proven anterior cruciate ligament rupture performed at our center were retrospectively evaluated for the presence of a meniscus, collateral ligament injury, a femoral impression, or a posterolateral impression fracture. Femoral impressions were described according to their local appearance and posterolateral tibial plateau fractures were described using the classification of Menzdorf et al.

Results In 29 cases a significant impression in the lateral femoral condyle was detected. There was a significantly increased number of lateral meniscal $(41.4 \%$ vs. $18.6 \% p=0.023)$ and medial ligament $(41.4 \%$ vs. $22.1 \% ; p=0.040)$ injuries in the group with a lateral femoral notch sign. 104 patients showed a posterolateral bone bruise or fracture of the tibial plateau. Seven of these required an intervention according to Menzdorf et al. In the group of anterior cruciate ligament injuries with posterolateral tibial plateau fracture significantly more lateral meniscus injuries were seen $(p=0.039)$.

Conclusion In the preoperative planning of ACL rupture accompanied with a positive femoral notch sign, attention should be paid to possible medial collateral ligament and lateral meniscus injuries. As these are more likely to occur together. A posterolateral impression fracture of the tibial plateau is associated with an increased likelihood of the presence of a lateral meniscal injury. This must be considered in surgical therapy and planning and may be the indication for necessary early surgical treatment.
\end{abstract}

Keywords ACL rupture $\cdot$ Posterolateral tibial plateau fracture $\cdot$ Femoral notch sign $\cdot$ Anterior cruciate ligament

Karl-Heinz Frosch

unfallchirurgie@uke.de

1 Department of Trauma and Orthopaedic Surgery, University Medical Center Hamburg-Eppendorf, Martinistrasse 52, 20246 Hamburg, Germany

2 Department of Diagnostic and Interventional Radiology and Nuclear Medicine, University Medical Center Hamburg-Eppendorf, Martinistrasse 52, 20246 Hamburg, Germany

3 CLARAHOF Clinic of Orthopaedic Surgery, University of Basel, Clarahofweg 19a, 4058 Basel, Switzerland

4 Department of Trauma Surgery, Orthopaedics and Sports Traumatology, BG Hospital Hamburg, Bergedorfer Straße 10, 21033 Hamburg, Germany

\section{Introduction}

The anterior cruciate ligament (ACL) rupture is one of the most common sports injuries (Fig. 1) [1]. As part of the mechanism of the injury, a valgus/internal rotation mechanism results in ventral subluxation of the tibia, and the lateral femoral condyle may strike the posterolateral tibial plateau. Depending on the force applied, there may be anything from edema to fractures in these areas [2-5]. Furthermore, this mechanism of injury is also associated with injury to the lateral meniscus posterior horn [6].

In at least 3 out of 4 cases, in addition to the ACL rupture, MRI can demonstrate bone edema in the posterolateral 


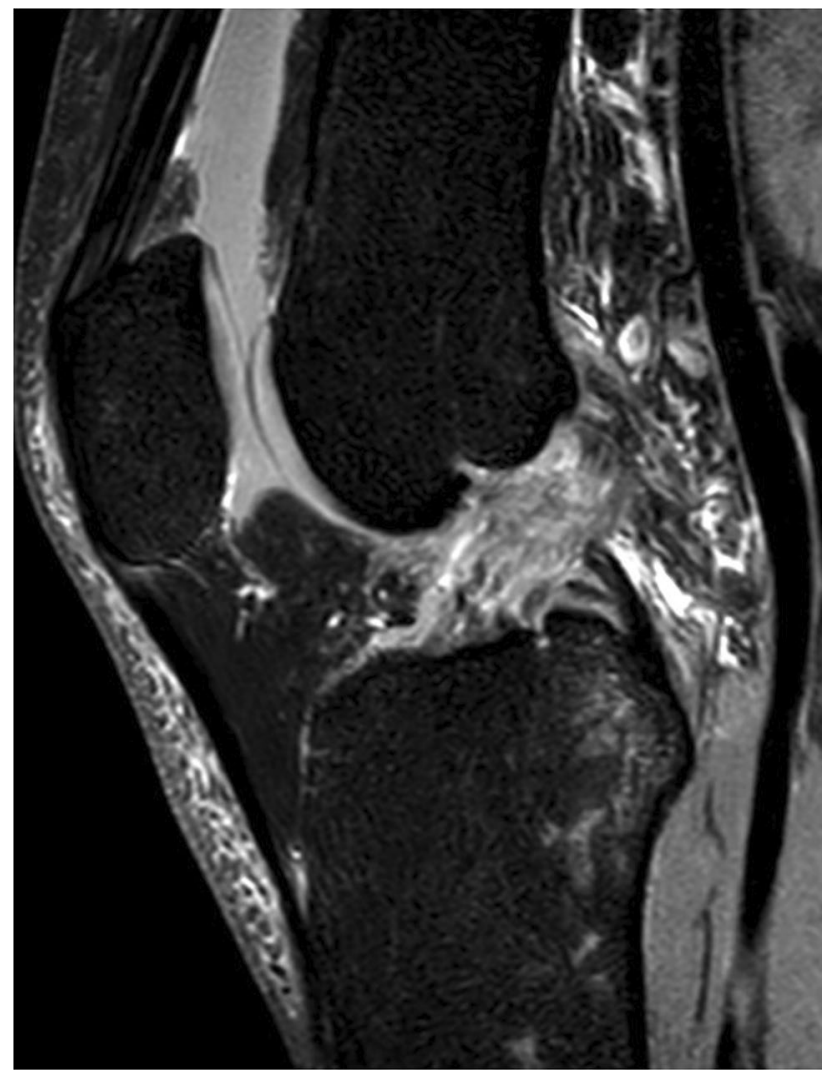

Fig. 1 MRI scan of a left Knee in saggital plane with a ACL rupture

tibial plateau region and at the lateral femoral condyle [7]. Described in the literature is the so-called lateral femoral notch sign (LFNS) with an impression of the lateral distal femur as well as the posterolateral fracture of the tibial plateau, which is typically localized in the posterolateral-lateral
(PLL) and posterolateral-central (PLC) segments according to the 10 segment classification of the German Knee Society [2, 8] (Figs. 2, 3).

Both fractures are considered predictive of ACL injury [2, 9-11]. For the LFNS, an incidence of $20-60 \%$ has been reported depending on the literature [10-14].

Due to the deformity of the joint surface in weight-bearing areas, early-onset osteoarthrosis may occur in the long term $[2,12,15]$. Therefore, accompanying injuries in particular must also be recognized and, if necessary, treated.

To our knowledge, no valid data exist yet for the incidence of posterolateral fractures requiring intervention in this group. In our opinion, there is still a lack of understanding with which ligamentous concomitant injuries besides the anterior cruciate ligament injury this osseous injury is associated. Furthermore, it is completely unclear when a posterolateral tibial fracture and when a fracture occurs in the lateral femoral articular surface.

We therefore reviewed 115 MRI scans with proven anterior cruciate ligament rupture for LFNS and the posterolateral fracture of the tibial plateau and their associated injuries.

\section{Methods}

A total of 115 MRI scans using a 3-Tesla MRI (Ingenia 3T Phillips) with confirmed anterior cruciate ligament rupture between July 2016 and October 2020 were included (Fig. 1).

MRI scans were followed up for the presence of meniscal injury, collateral ligament injury, significant impression
Fig. 2 Illustration of an MRI of a left knee joint in A saggital section plane showing a lateral notch sign (arrow) and a basket handle tear (cross) of the external meniscus and $\mathbf{B}$ in coronal section plane showing a lateral notch sign
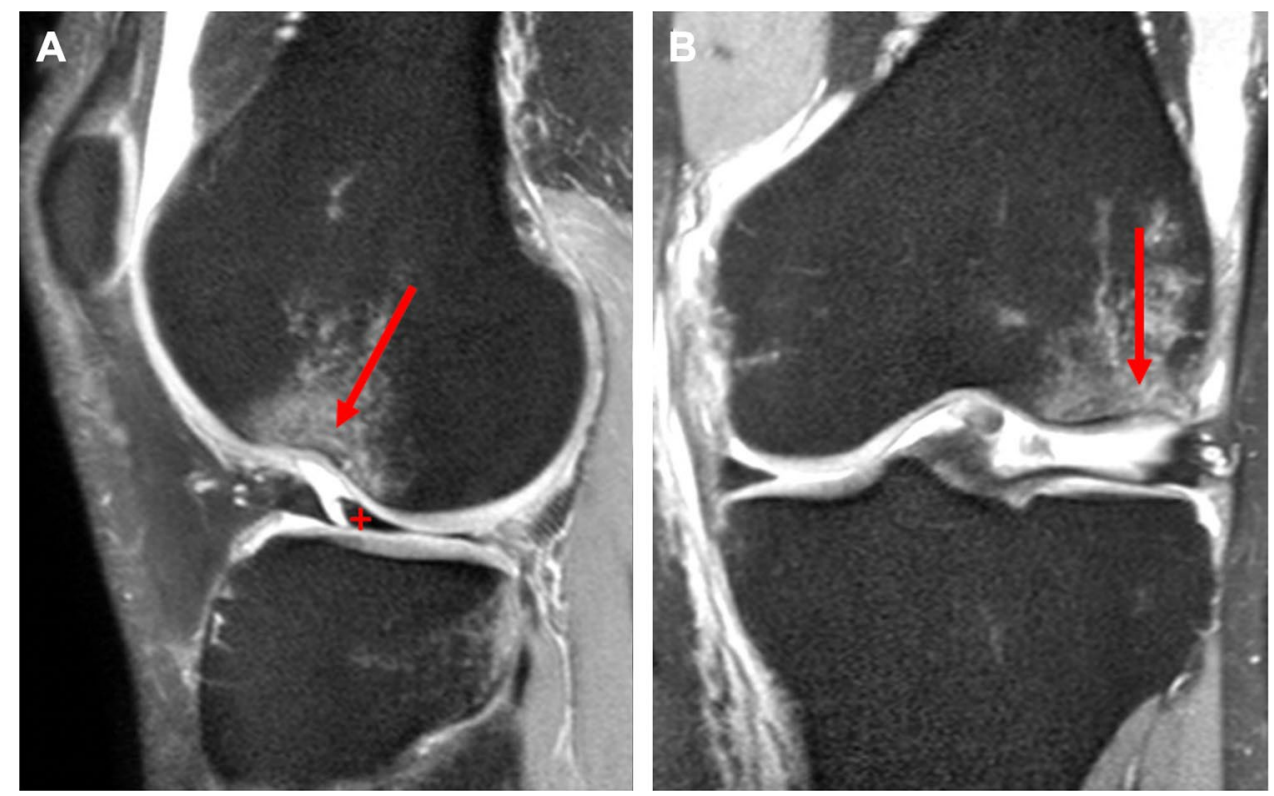
Fig. 3 Illustration of an MRI of a left knee joint in A saggital section plane showing a posterolateral fracture of the tibial plateau (arrow) and B transversal section plane showing a posterolateral fracture of the tibial plasteau
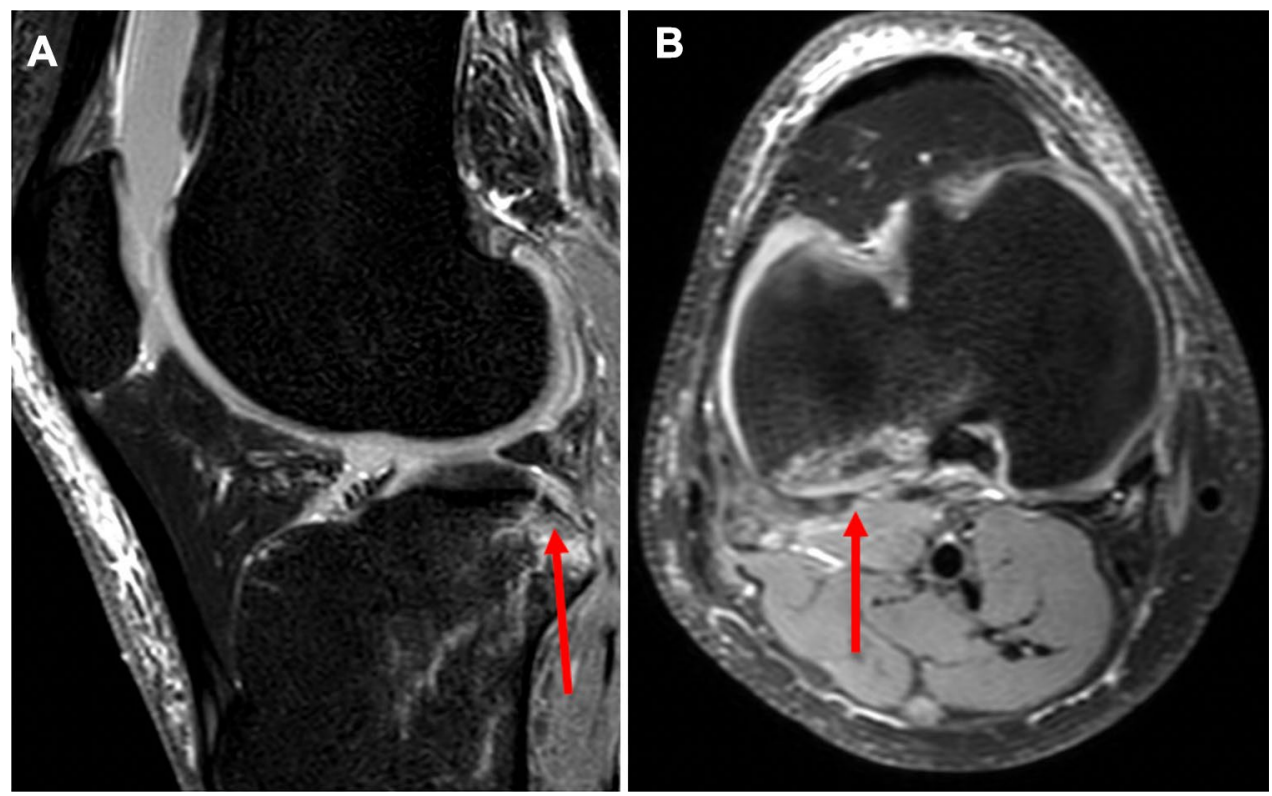

( $>2 \mathrm{~mm}$ ) of the lateral femoral condyle, the LFNS (Fig. 2), and posterolateral fracture of the tibial plateau (Fig. 3).

No differences were made regarding the morphology of the collateral ligament injury (e.g., proximal/ distal avulsion, intraligamentous rupture) or the meniscal injuries (e.g., flap tear, root tear etc.).

The femoral impression was characterized on the basis of the depth of the impression in the sagittal planes. A line corresponding to the shape of the femoral condyle without impression was drawn and the depth of the impression was measured from this line to the osseous base at the deepest point (Fig. 4). To describe the location of the impression the sagittal femoral condyle was divided into 4 quadrants by drawing 3 lines at the lowest point of the impression. The most ventral and dorsal lines represented the distal extension of the femoral shaft. The median bisects the central region (Fig. 4).

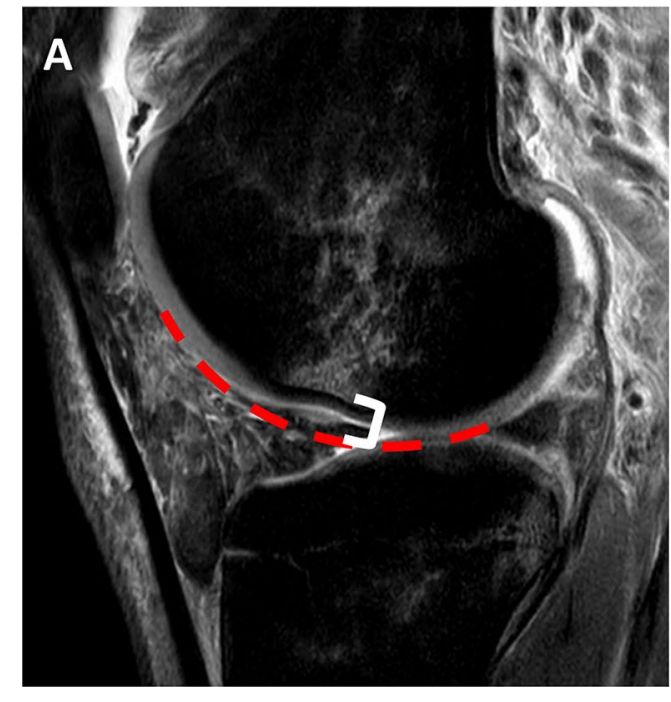

Fig. 4 A Measurement of the lateral femoral impression: the red elliptical line shows the femoral articular surface without the impression, the white bracket represents the impression depth starting from the red line to the bottom of the osseous impression, measured at the deepest point. B Determination of the localization of the femoral impression. The sagittal femoral condyle is divided into 4 quadrants

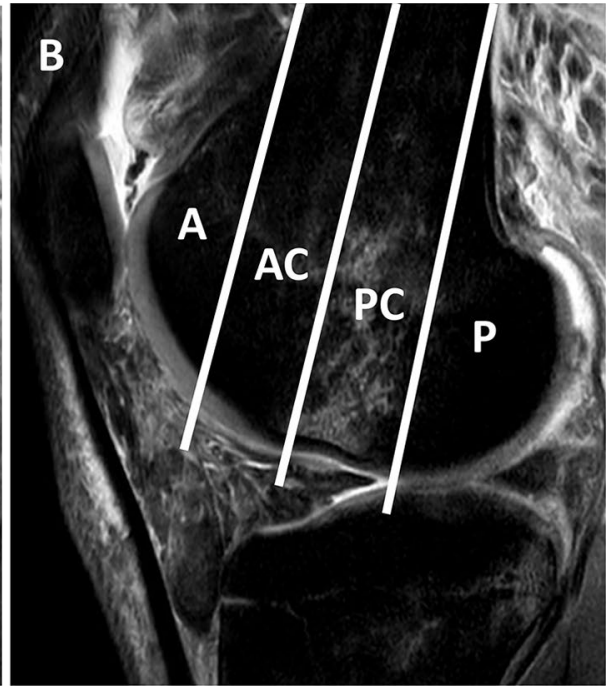

by drawing 3 lines at the deepest point of the impression. The most ventral and dorsal lines represented the distal extension of the femoral shaft. The median bisects the central region. $A$ anterior quadrant, $A C$ antero-central quadrant, $P C$ postero-central quadrant, $P$ posterior quadrant 
Fig. 5 Classification of posterolateral impression fractures modified of Menzdorf et al. [2]. Three different entities are distinguished: rim fractures (1), depression fractures (2) and shear fractures (3). These 3 groups are each subdivided. The decisive factor is whether more than $50 \%$ of the posterior horn of the lateral meniscus is supported by bone and whether there is a dislocation of less than $2 \mathrm{~mm}$ depth. If this is the case, the respective fracture type is assigned the letter $\mathbf{a}$. If this is not the case, the fracture form is assigned the letter $\mathbf{b}$, whereby the criteria mentioned decide on the need for surgery. Within the group of "rim fractures" there is another separate entity: the " $90^{\circ}$ deformity", to which the letter $\mathbf{c}$ is assigned. Within the group of depression fractures, there is a subgroup that is also assigned a, c. In this group, $100 \%$ of the posterior horn of the lateral meniscus are not supported by the posterolateral plateau and there is a dislocation of more than $2 \mathrm{~mm}$ depth
$1 \mathrm{a}$

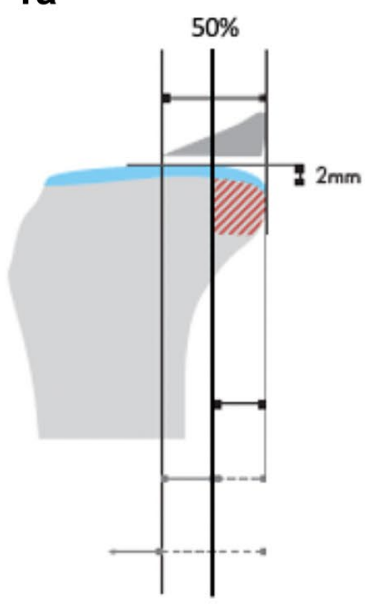

$2 a$

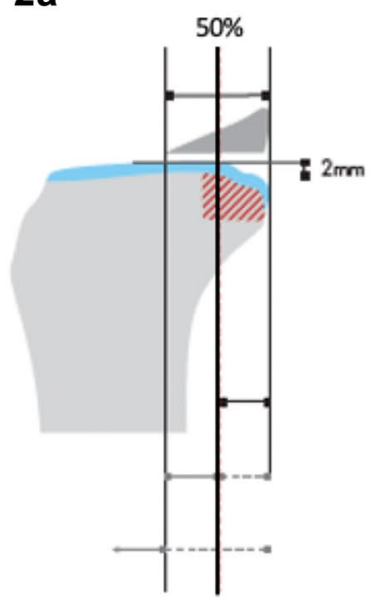

$3 a$

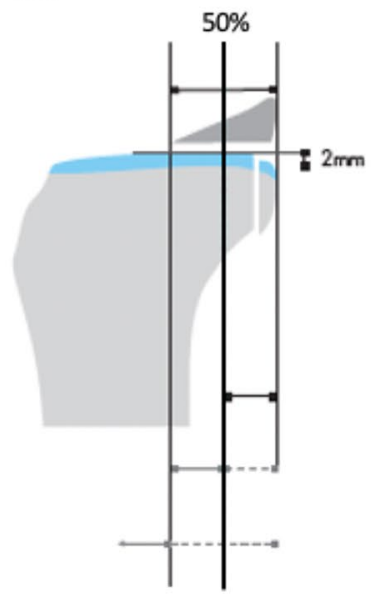

$1 b$

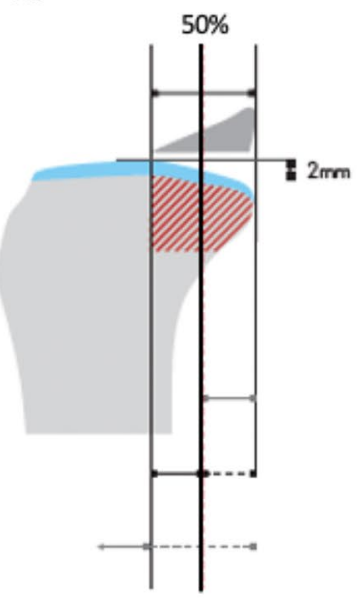

2b

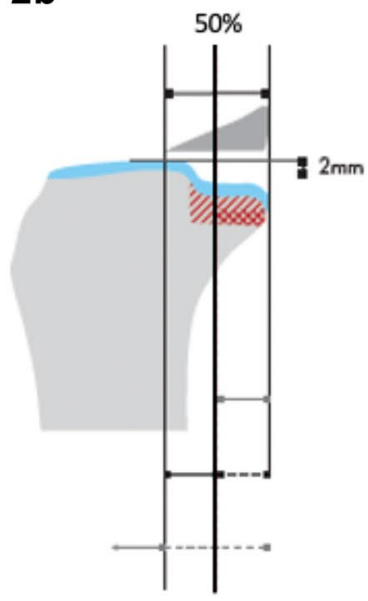

2c

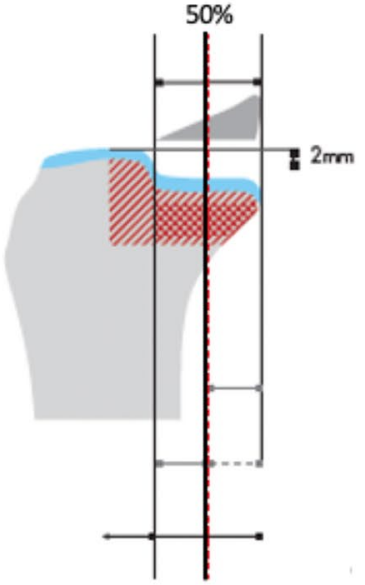

1c

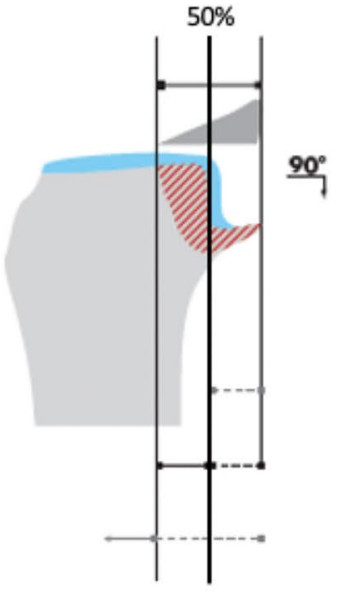

$90^{\circ}$
$3 b$

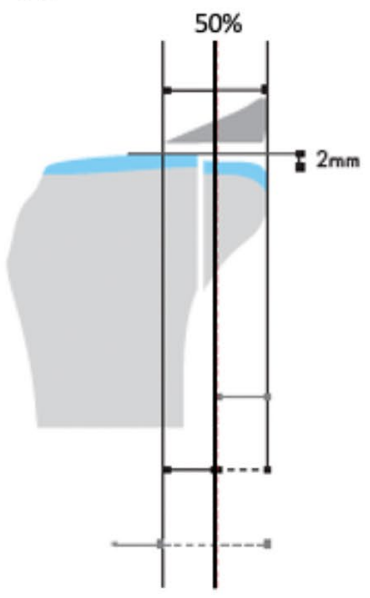


horn of the lateral meniscus is supported by bone and whether there is a dislocation of less than $2 \mathrm{~mm}$ depth. If this is the case, the respective fracture type is assigned the letter a. If this is not the case, the fracture form is assigned the letter $b$, whereby the criteria mentioned decide on the need for surgery. Within the group of "rim fractures" there is another separate entity: the " $90^{\circ}$ deformity", to which the letter $\mathrm{c}$ is assigned. Within the group of depression fractures, there is a subgroup that is also assigned a, c. In this group, $100 \%$ of the posterior horn of the lateral meniscus are not supported by the posterolateral plateau and there is a dislocation of more than $2 \mathrm{~mm}$ depth.

The study was conducted after a positive ethical vote of the resident ethics board.

\section{Statistical analysis}

A Shapiro-Wilk normality test and Kolmogorov-Smirnov test were performed to determine if the data were normally distributed. Pearson and Spearman coefficient was used for correlation of parametric and nonparametric data, respectively. Comparison of binominal data was performed using Fisher's exact test. Comparison of two paired groups with parametric and nonparametric data was performed using paired $t$ test and Wilcoxon signed rank test, respectively. Comparison of two unpaired groups with parametric and nonparametric data was performed using independent $t$ test and Mann-Whitney $U$ test, respectively. The level of significance for all tests was set at $p \leq 0.05$. All data were analyzed using IBM SPSS Statistics version 26.0 (IBM, Armonk, NY).

\section{Results}

In the entire patient collective, 104 patients (90.43\%) showed posterolateral bone bruise with minor impaction of the tibial head and 29 (25.3\%) significant impressions in the lateral femoral condyle.

Seven posterolateral fractures of the tibial plateau required intervention according to Menzdorf et al. [2]. This results in an incidence of $6.1 \%$ for posterolateral fractures requiring intervention in the setting of anterior cruciate ligament injuries in our collective.

Overall, we saw 29 impressions (25.3\%) in the lateral femoral condyle. Within this group, significantly more males $(n=23)$ than females $(n=6)$ were affected $(p=0.016)$. Furthermore, the patient population with femoral impression tended to be older $(33.3 \pm 11.7)$ compared to the group without significant impression $(30.6 \pm 9.2 ; p=0.03)$.

Analysis of concomitant injury in patients with $(n=29)$ versus without $(n=86)$ femoral impression showed that within the group with femoral impression there were
Table 1 Demographics and concomitant injuries in patients with $(N=29)$ vs. without $(N=86)$ bump in 115 patients with ruptured anterior crucial ligament

\begin{tabular}{llll}
\hline Parameter & $\begin{array}{l}\text { Patients with poste- } \\
\text { rolateral impaction }\end{array}$ & $\begin{array}{l}\text { Patients without pos- } \\
\text { terolateral impaction }\end{array}$ & P value \\
\hline Gender & & 46 & 0.016 \\
Male & 23 & 40 & \\
Female & 6 & $30.6 \pm 9.2$ & $0.003^{\ddagger}$ \\
Age [years] & $33.3 \pm 11.7$ & 21 & \\
Medial meniscus tear & 6 & 65 & $0.803^{\dagger}$ \\
Yes & 23 & & \\
No & 12 & 16 & $0.023^{\dagger}$ \\
Lateral meniscus tear & 70 & \\
Yes & 17 & & $0.040^{\dagger}$ \\
No & 17 & 19 & \\
MCL rupture & & 67 & $0.159^{\dagger}$ \\
Yes & 12 & & \\
No & 17 & 27 & 59
\end{tabular}

'Using Fisher's exact test

'Using Mann-Whitney $U$ test

significantly more lateral meniscal injuries $(41.4 \%$ vs. $18.6 \% ; p=0.023)$ as well as medial ligament injuries $(41.4 \%$ vs. $22.1 \%$; $p=0.040$ ) (Table 1 ).

Impression of the femoral condyle was localized anterocentral in one patient (3.4\%), antero-central and posterocentral in 13 patients (44.8\%), and isolated to the posterocentral quadrant in 14 patients (48.3\%). One patient (3.4\%) showed the impression localized in 3 quadrants. No patient had an impression in the posterior quadrant.

Posterolateral fracture of the tibial head requiring intervention according to Menzdorf et al. was not seen in any patient within the group with lateral femoral impression. There were 27 rim fractures type 1a and one depression fracture type 2 a according to Menzdorf et al. which did not result in any surgical consequences [2].

The group without femoral notch sign showed a total of 76 posterolateral edema including fractures $(88.4 \%)$, of which $7(8.4 \%)$ required intervention (type $1 \mathrm{~b}: n=4$, type 1c: $n=3$ ) according to Menzdorf et al. [2]. There was no statistically significant difference between the two groups $(p=0.286$, Table 2).

The mean age of the patients was $29.8 \pm 5.1$ years in the group of patients without posterolateral fracture and $30.7 \pm 10.0$ years in the group with fracture without significant difference $(p=0.868)$. However, the patients with posterolateral fracture requiring intervention showed significantly older age at $36.6 \pm 9.7$ years than the patients without lateral tibial plateau impression fracture requiring 
Table 2 Incidence and classification of poserotlateral tibial plateau fractures depending on the presence of femoral notch sign $(N=29)$ or in the absence of femoral notch sign $(N=86)$

\begin{tabular}{lclc}
\hline Parameter & $\begin{array}{l}\text { Patients with femo- } \\
\text { ral notch sign }\end{array}$ & $\begin{array}{l}\text { Patients without } \\
\text { femoral notch sign }\end{array}$ & $p$ value \\
\hline \multicolumn{2}{l}{ PL tibia impression } & & \\
Yes & 28 & 76 & $0.286 \dagger$ \\
No & 1 & 10 & $0.488^{*}$ \\
PL tibial impression classification & & \\
1a & 27 & 60 & \\
1b & 0 & 4 & \\
$1 \mathrm{c}$ & 0 & 3 & \\
$2 \mathrm{a}$ & 1 & 8 & \\
$2 \mathrm{~b}$ & 0 & 1 & \\
$2 \mathrm{c}$ & 0 & 0 & \\
$3 \mathrm{a}$ & 0 & 0 & \\
$3 \mathrm{~b}$ & 0 & 0 & \\
\hline
\end{tabular}

†Using Fisher's exact test

†Using Mann-Whitney $U$ test

intervention at $29.8 \pm 9.5$ years $(p=0.029)$. Gender distribution showed no significant difference in both groups $(p=0.351)$.

In addition, we saw significantly more lateral meniscus injuries in the group with a posterolateral fracture $(p=0.039)$ than in the group without a posterolateral fracture. We did not see a correlation with medial meniscus injuries $(p=1.000)$, lateral collateral ligament injuries $(p=1.000)$ or medial collateral ligament injuries $(p=0.484$, Table 3$)$.

\section{Discussion}

We were able to show that the incidence of fractures of the posterolateral tibial plateau requiring surgery is significantly higher than expected at $8.4 \%$. The incidence of fractures of the lateral femoral condyle (25.3\%) is within the range of $20-60 \%$ described in the literature $[10,12,13]$. The vast majority of the lateral femoral impression in our patient population is in the main weight-bearing area, which is in agreement with the data of Hoffenler et al. [13].

Here, the patients with a posterolateral fracture of the tibial plateau requiring surgery are significantly older than the patients without a fracture $(p=0.029)$. In the group of patients with a lateral femoral impression, an medial collateral ligament injury $(p=0.040)$ and an injury of the lateral meniscus $(p=0.023)$ were significantly more frequent. In addition, the presence of a posterolateral tibial plateau fracture was significantly more likely to result in a lateral meniscus injury $(p=0.039)$.

The incidence of $25.3 \%$ for femoral lateral impressions in our patient population is consistent with the recent study by
Table 3 Demographics and concomitant injuries in patients with $(N=104)$ vs. without $(N=11)$ posterolateral impaction in patients with ruptured anterior crucial ligament

\begin{tabular}{llll}
\hline Parameter & $\begin{array}{l}\text { Patients with poste- } \\
\text { rolateral impaction }\end{array}$ & $\begin{array}{l}\text { Patients without pos- } \\
\text { terolateral impaction }\end{array}$ & $p$ value \\
\hline Gender & & 7 & $1.000^{\dagger}$ \\
Male & 62 & 4 & $0.868^{\dagger}$ \\
Female & 42 & $29.8 \pm 5.1$ & \\
Age [years] & $30.7 \pm 10.0$ & 1 & $0.286^{\dagger}$ \\
Lateral femoral notch sign & 10 & \\
Yes & 28 & & \\
No & 76 & 4 & $0.283^{\dagger}$ \\
Medial meniscus tear & 23 & 7 & \\
Yes & 81 & & $0.039^{\dagger}$ \\
No & 28 & 0 & \\
Lateral meniscus tear & 11 & \\
Yes & 28 & & \\
No & 76 & 4 & $0.484^{\dagger}$ \\
MCL rupture & & 7 & \\
Yes & 27 & 3 & \\
No & 77 & 8 & \\
LCL rupture & & &
\end{tabular}

'Using Fisher's exact test

${ }^{\ddagger}$ Using Mann-Whitney $U$ test

Bernholt et al. and Herbst et al., who found an incidence of $25.8 \%$ and $26.3 \%[14,16]$. However, Bernholdt et al. defined any femoral impression $>1.5 \mathrm{~mm}$ as a significant impression [16]. Lucidi et al. showed that the presence of a LFNS deeper than $2 \mathrm{~mm}$ could be used for the preoperative identification of patients with a high risk of increased rotatory instability [17]. Furthermore, Miller et al. found an ACL injury in $70 \%$ of patients when the lateral femoral notch was deeper than $1.5 \mathrm{~mm}$, and in $100 \%$ of the cases when the lateral femoral notch was deeper than $2.0 \mathrm{~mm}$ [18]. Further studies by Delzell et al. and Herbst et al. postulate a cut off of $2 \mathrm{~mm}$ for the LFNS [14, 19], which is why we decided to use a $2 \mathrm{~mm}$ cut off. In the current literature, there are no recommendations as to when surgical reduction of the femoral impression should be performed. But it is known that due to the deformity of the joint surface in weight-bearing areas, early-onset osteoarthrosis may occur in the long term [12, 15]. Therefore a surgical consequence results at an impression $>2 \mathrm{~mm}$ in our department.

If there is a significant lateral impression of the femoral condyle, the presence of a possible injury of the medial collateral ligament must be checked. In this regard, our data are consistent with the study by Bernholt et al. [16]. This does not seem surprising when the mechanism of the accident is taken into account. Thus, when the LFNS occurs, a 
significant valgus stress seems to occur as part of the valgus/ internal rotation mechanism, leading to the corresponding impression and injury of the medial collateral ligament.

In contrast to Bernholt et al., the presence of a posterolateral tibial fracture requiring intervention according to Menzdorf et al. and a combined significant impression of the lateral femoral condyle seem to be excluded in our patient collective $[2,16]$. However, in all patients with a LFNS, we saw an impression in the posterolateral quadrant of the tibial plateau, which, however, did not represent a need for surgery according to the defined criteria of Menzdorf et al. [2]. This may be due to the fact that we defined impressions of the lateral femoral condyle of $>2 \mathrm{~mm}$ as cut off for LFNS as previously described. In addition, the criteria previously mentioned by Menzdorf et al. for surgical treatment associated with increased instability as well as an increased posttraumatic osteoarthritis rate and thus entailing a therapeutic consequence were applied [2, 20-22]. Thus, the criteria applied in this study that have an immediate therapeutic consequence appear to not intersect.

The association with the injury of the lateral meniscus also seems logical in the light of the mechanism of an ACL injury and is consistent with the current literature. However, injury to the lateral meniscus in acute trauma also entails a therapeutic consequence and must be considered [6].

The incidence of posterolateral tibial plateau fractures requiring intervention at $6.7 \%$ is significantly higher than expected. This is even higher in the group of patients with a posterolateral bone bruise at $8.4 \%$. So Bernholt et al. observed a lateral tibial plateau depth bone loss percentage of greater than $10 \%$ in $8.6 \%$ of all patients in primary ACL tear cohort. However, it remains unclear whether Bernholt et al. infer a need for surgery from this [16]. Therefore, it seems reasonable to use a classification from which a treatment recommendation can be derived. The classification according to Menzdorf et al. gives clear criteria for surgical treatment. Namely, dislocation of the fracture of $2 \mathrm{~mm}$ or more and/ or extension beyond half of the posterior horn of the lateral meniscus [2, 20, 22]. The above criteria lead to increased pivot shift and thus significant posterolateral instability in concomitant ACL rupture [2, 20].

This must be considered in surgical therapy. In our hands, the vast majority of posterolateral fractures, indicated for surgery, can be arthroscopically addressed as part of cruciate ligament reconstruction [23]. In addition, in the presence of a posterolateral fracture or even just edema, a high rate of injuries to the lateral meniscus should be expected [16, 24].

\section{Limitations}

The patient collective of 115 patients is relatively small. Different morphologies of collateral ligament injury as well as meniscus injuries were not analyzed, so that no statement can be made about the necessity of surgical treatment. Results of clinical examinations with regard to existing instabilities are not available.

\section{Conclusion}

ACL ruptures may be associated with osseous as well as concomitant soft tissue injuries. In particular, the incidence of fractures requiring treatment is significantly higher than expected. In our patient population, older patients tend to be affected.

In case of a positive LFNS, the presence of an lateral meniscus as well as an medial collateral ligament injury should be considered in the preoperative planning. Posterolateral fracture of the tibial plateau is associated with increased likelihood of the presence of a lateral meniscus injury.

Therefore, the presence of different form of posterolateral tibial plateau fractures requiring intervention in the setting of an anterior cruciate ligament injury must be considered in the presence of other associated soft tissue injuries.

Further studies with a larger cohort appear useful for confirmation. In particular, a prospective study of lateral femoral notch fractures in terms of functional outcome would be desirable to formulate clear criteria for surgical reduction in the future.

Author contribution KHF, JPK, GP, AK, MK conceived the project, the main conceptual ideas and the proof sketch. GP, JPK, AK wrote the manuscript. JPK, AK and WM performed the data analysis. All authors discussed the results and contributed to the final manuscript.

Funding Open Access funding enabled and organized by Projekt DEAL. No external source of funding was used.

\section{Declarations}

Conflict of interest The authors declare that they have no conflict of interest.

Ethical approval This article does not contain any studies with human participants or animals performed by any of the authors.

Informed consent For this type of study informed consent is not required.

Open Access This article is licensed under a Creative Commons Attribution 4.0 International License, which permits use, sharing, adaptation, distribution and reproduction in any medium or format, as long as you give appropriate credit to the original author(s) and the source, provide a link to the Creative Commons licence, and indicate if changes were made. The images or other third party material in this article are included in the article's Creative Commons licence, unless indicated otherwise in a credit line to the material. If material is not included in the article's Creative Commons licence and your intended use is not 
permitted by statutory regulation or exceeds the permitted use, you will need to obtain permission directly from the copyright holder. To view a copy of this licence, visit http://creativecommons.org/licenses/by/4.0/.

\section{References}

1. Sanders TL, Maradit Kremers H, Bryan AJ et al (2016) Incidence of anterior cruciate ligament tears and reconstruction: a 21-year population-based study. Am J Sports Med 44:1502-1507. https:// doi.org/10.1177/0363546516629944

2. Menzdorf L, Drenck T, Akoto R et al (2020) Clinical results after surgical treatment of posterolateral tibial plateau fractures ("apple bite fracture") in combination with ACL injuries. Eur J Trauma Emerg Surg 46:1239-1248. https://doi.org/10.1007/ s00068-020-01509-8

3. Cobby MJ, Schweitzer ME, Resnick D (1992) The deep lateral femoral notch: an indirect sign of a torn anterior cruciate ligament. Radiology 184:855-858. https://doi.org/10.1148/radiology.184.3. 1509079

4. Jiang L, Wu H, Yan S (2015) Two cases of contact anterior cruciate ligament rupture combined with a posterolateral tibial plateau fracture. Case Rep Orthop 2015:1-5. https://doi.org/10.1155/ 2015/250487

5. Krause M, Menzdorf L, Preiss A, Frosch K-H (2018) Are there four tibial plateau columns? Yes there are, as illustrated by a postero-lateral apple-bite fracture. Response to a letter-to-the-editor. Int Orthopaedics (SICOT) 42:443-446. https://doi.org/10.1007/ s00264-017-3686-9

6. Hagino T, Ochiai S, Senga S et al (2015) Meniscal tears associated with anterior cruciate ligament injury. Arch Orthop Trauma Surg 135:1701-1706. https://doi.org/10.1007/s00402-015-2309-4

7. Patel SA, Hageman J, Quatman CE et al (2014) Prevalence and location of bone bruises associated with anterior cruciate ligament injury and implications for mechanism of injury: a systematic review. Sports Med 44:281-293. https://doi.org/10.1007/ s40279-013-0116-Z

8. Krause M, Preiss A, Müller G et al (2016) Intra-articular tibial plateau fracture characteristics according to the "Ten segment classification.” Injury 47:2551-2557. https://doi.org/10.1016/j. injury.2016.09.014

9. Stallenberg B, Gevenois PA, Sintzoff SA et al (1993) Fracture of the posterior aspect of the lateral tibial plateau: radiographic sign of anterior cruciate ligament tear. Radiology 187:821-825. https:// doi.org/10.1148/radiology.187.3.8497638

10. Murphy BJ, Smith RL, Uribe JW et al (1992) Bone signal abnormalities in the posterolateral tibia and lateral femoral condyle in complete tears of the anterior cruciate ligament: a specific sign? Radiology 182:221-224. https://doi.org/10.1148/radiology.182.1. 1727286

11. Berthold DP, Muench LN, Herbst E et al (2021) High prevalence of a deep lateral femoral notch sign in patients with anterior cruciate ligament (ACL) and concomitant posterior root tears of the lateral meniscus. Knee Surg Sports Traumatol Arthrosc 29:10181024. https://doi.org/10.1007/s00167-020-06071-9

12. Tauber M, Fox M, Koller H et al (2008) Arthroscopic treatment of a large lateral femoral notch in acute anterior cruciate ligament tear. Arch Orthop Trauma Surg 128:1313-1316. https://doi.org/ 10.1007/s00402-007-0535-0

13. Hoffelner T, Pichler I, Moroder P et al (2015) Segmentation of the lateral femoral notch sign with MRI using a new measurement technique. BMC Musculoskelet Disord 16:217. https://doi.org/10. 1186/s12891-015-0677-0

14. Herbst E, Hoser C, Tecklenburg K et al (2015) The lateral femoral notch sign following ACL injury: frequency, morphology and relation to meniscal injury and sports activity. Knee Surg Sports Traumatol Arthrosc 23:2250-2258. https://doi.org/10.1007/ s00167-014-3022-5

15. Sadlo PA, Nebelung W (2006) Arthroscopically assisted reduction of a lateral femoral notch in acute tear of the anterior cruciate ligament. Arthroscopy J Arthrosc Related Surg 22:574.e1-574.e3. https://doi.org/10.1016/j.arthro.2005.11.006

16. Bernholt DL, DePhillipo NN, Crawford MD et al (2020) Incidence of displaced posterolateral tibial plateau and lateral femoral condyle impaction fractures in the setting of primary anterior cruciate ligament tear. Am J Sports Med 48:545-553. https://doi.org/10. $1177 / 0363546519895239$

17. Lucidi GA, Grassi A, Di Paolo S et al (2021) The lateral femoral notch sign is correlated with increased rotatory laxity after anterior cruciate ligament injury: pivot shift quantification with a surgical navigation system. Am J Sports Med 49:649-655. https:// doi.org/10.1177/0363546520982002

18. Miller LS, Yu JS (2010) Radiographic indicators of acute ligament injuries of the knee: a mechanistic approach. Emerg Radiol 17:435-444. https://doi.org/10.1007/s10140-010-0876-9

19. Delzell PB, Schils JP, Recht MP (1996) Subtle fractures about the knee: innocuous-appearing yet indicative of significant internal derangement. Am J Roentgenol 167:699-703. https://doi.org/10. 2214/ajr.167.3.8751684

20. Herbort M (2020) The "Bankart Knee": biomechanical consequences of a posterolateral tibia plateau impression fracture as concomitant injury of ACL rupture, AGA 2020, AGA 20-273

21. Parkkinen M, Madanat R, Mustonen A et al (2014) Factors predicting the development of early osteoarthritis following lateral tibial plateau fractures: mid-term clinical and radiographic outcomes of 73 operatively treated patients. Scand J Surg 103:256262. https://doi.org/10.1177/1457496914520854

22. Singleton N, Sahakian V, Muir D (2017) Outcome after tibial plateau fracture: how important is restoration of articular congruity? J Orthop Trauma 31:158-163. https://doi.org/10.1097/BOT.00000 00000000762

23. Ackermann C, Frings J, Alm L, Frosch K-H (2019) Arthroscopic controlled closed reduction and percutaneous fixation of posterolateral tibia plateau impression fractures. Arthrosc Tech 8:e867e874. https://doi.org/10.1016/j.eats.2019.04.001

24. Bernholt DL, DePhillipo NN, Grantham WJ et al (2020) Morphologic variants of posterolateral tibial plateau impaction fractures in the setting of primary anterior cruciate ligament tear. Am J Sports Med 48:318-325. https://doi.org/10.1177/0363546519893709

Publisher's Note Springer Nature remains neutral with regard to jurisdictional claims in published maps and institutional affiliations. 